\title{
La figura de Spinoza en El Teatro Crítico Universal de Benito Feijoo
}

\section{Spinoza's figure in Benito Feijoo 's Universal Critical Theater}

\author{
NATALIA SABATER \\ Universidad de Buenos Aires, CONICET
}

Recibido: 13/03/2020 Aceptado:20/03/2020

\begin{abstract}
RESUMEN
El objetivo del presente trabajo es rastrear cuál es el semblante que el padre benedictino Benito Feijoo construye de la figura de Baruch Spinoza en su Teatro Crítico Universal. El estudio de las referencias al nombre del filósofo holandés presentes en la obra feijoniana es fundamental en tanto éstas permiten delimitar un comienzo en la recepción del spinozismo en la primera ilustración española. La hipótesis que se defenderá es que Spinoza es un interlocutor constante de Feijoo, que reviste importancia, que es convocado al diálogo filosófico pero, al mismo tiempo, es presentado estratégicamente de manera solapada, disimulada, distante.
\end{abstract}

PALABRAS CLAVE

RECEPCIÓN FILOSÓFICA, FEIJOO, SPINOZA, ILUSTRACIÓN ESPAÑOLA

\begin{abstract}
The following paper attempts to trace the characterization that Benito Feijoo builds on the figure of Baruch Spinoza in his Universal Critical Theater. The study of the references to the name of the Dutch philosopher present in the Feijonian work is fundamental as they represent a beginning in the reception of Spinozism in the first Spanish illustration. The hypothesis that will be defended is that Spinoza is an important and constant reference to Feijoo, but, at the same time, it is presented strategically in a disguised and distant way.

KEYWORDS

PHILOSOPHICAL RECEPTION, FEIJOO, SPINOZA, SPANISH ILLUSTRATION
\end{abstract}

(C) Contrastes. Revista Internacional de Filosofía, vol. XXVI Nº1 (2021), pp. 7-25. ISSN: 1136-4076

Departamento de Filosofía, Universidad de Málaga, Facultad de Filosofía y Letras

Campus de Teatinos, E-29071 Málaga (España) 


\section{INTRODUCCIÓN}

LA FILOSOFÍA SPINOZISTA - de la mano de su proyecto ético, antropológico, político- ha tenido una vasta recepción en la modernidad tardía y en importantes autores del pensamiento contemporáneo occidental. Su gravitación en los debates filosóficos de la Alemania ilustrada (Dujovne 1941; Solé 2011), su presencia en Francia en los siglos XVIII y XIX (Vèrniere 1954; Prélorentzos 1994) revelan que Spinoza ocupó un lugar central como fuente, como referencia, como interlocutor, en el desarrollo de nuevos movimientos filosóficos europeos. Sin embargo, la recepción del spinozismo en tierras españolas resulta más fragmentaria y difícil de rastrear. Por un lado, los estudios al respecto son escasos (Domínguez 1994; Fernández García 2018) pero esto se debe, en último término, a que las menciones y alusiones al pensador holandés, especialmente en el seno de la ilustración católica, no son muchas. ¿Cómo reconstruir el acogimiento y el destino de la figura de Baruch Spinoza, luego de su muerte, en España? ¿Qué lugar ocupó su obra en dichas tierras durante el siglo XVIII? ¿Por dónde comenzar a delinear una recepción española de su pensamiento? Para responder estos interrogantes resulta necesario acudir a la filosofía del padre benedictino Benito Feijoo, uno de los más famosos exponentes de la primera Ilustración española, en cuyas obras encontramos referencias centrales, aunque enigmáticas, a Spinoza. Menciones que rompen el silencio, que representan las únicas apariciones del nombre de aquel judío holandés en España en el período que va desde 1648 a 1759 (Domínguez 1994, p. 17). ${ }^{1}$ Este valiente gesto de Feijoo de aludir a Spinoza, en un contexto en el que pesaba todavía la censura, nos ofrece un punto de partida, un abrevadero para comenzar a explorar la presencia de aquel en el siglo XVIII español. Es por ello que el presente trabajo buscará rastrear cuál es el semblante que el benedictino construye de la figura de Baruch en una de sus grandes obras filosóficas: el Teatro Crítico Universal, publicado en ocho tomos entre 1726 y $1739 .^{2}$ Dicho estudio consistirá, específicamente,

1 Domínguez señala que, además de la referencia que introduce Feijoo, habría aparentemente otra noticia sobre la presencia de Spinoza en España en el mencionado período, atribuida al profesor de Salamanca y después cardenal José Saenz de Aguirre. Éste «citaría a Spinoza ya en 1673, es decir, antes de morir y de que se publicaran sus obras póstumas», mención que resulta verdaderamente sorprendente y que no ha sido, en principio, estudiada en profundidad. Al respecto, Domínguez señala que no ha podido confirmar dicha referencia y remite a «R. Ceñal: La filosofia española del siglo XVII, Rev. Univers. Madrid 11 (1962) 377». Afirma: «No parece referirse a "Philosophia novantiqua" (Salamanca, 2 vol., 1672-3: comentario a libros de filosofía natural de Aristóteles), que hemos hojeado, sino a "Phil. Rationalis novantiqua" (Salamanca, 2 vol., 1672: comentario a la lógica y a la metafísica)».

2 A lo largo del Teatro Crítico, se alude en siete oportunidades a Spinoza, en diferentes discursos de distintos volúmenes. Aquí nos referiremos a seis de ellas, que concentran, en nuestra 
en el abordaje de aquellos pasajes en los que se hace una mención explícita al nombre del filósofo holandés, a partir de los cuales surgirán líneas posibles de lectura. La hipótesis que defenderemos es que Spinoza es un interlocutor constante de Feijoo, que reviste importancia, que es convocado al diálogo filosófico, pero, al mismo tiempo, es presentado estratégicamente de manera solapada, disimulada, distante.

Antes de comenzar, nos parece necesario decir unas palabras sobre quien representará el centro de análisis de las siguientes páginas. Benito Jerónimo Feijoo nació en Galicia en 1676. A los doce años ingresó en la Orden Benedictina - lo que supuso una renuncia a sus derechos de herencia- donde se consagró al estudio y logró el nombramiento de Maestro General. En 1709 se instala en la Universidad de Oviedo -luego de acceder por un concurso de oposición a la cátedra de Teología- en donde residió hasta el final de sus días en 1764. Si bien su formación intelectual estuvo ligada a la tradición escolástica, Feijoo se caracterizó por ser un autor ávido de nuevas fuentes, de lecturas disidentes, actitud que está en relación directa con su interés en liberar a la filosofía de la sujeción férrea a los dogmas, de fomentar la reflexión crítica y sincera. A pesar de que ello lo haya convertido en un autor polémico, en un sentido heterodoxo, no es menor señalar que, luego de Cervantes y Quevedo, es el español más editado del siglo XVIII (de Olaso 1981, p. 33). Los numerosos volúmenes publicados por este monje benedictino fueron escritos en un español accesible, no en latín, y se caracterizaron por una estructura sencilla, propia del género ensayístico, por un estilo directo, en un sentido informal. ${ }^{3}$ Tenían entre sus principales intenciones introducir al lector español en las polémicas filosóficas de Europa central, acercar a las tierras de la península aquellos debates fundamentales que habían surcado la primera modernidad, realizando un análisis crítico de ellos. Y estas características lo convirtieron en un filósofo sumamente influyente en su región, cuyas obras ya en ese entonces habían recibido 15 ediciones y contaban con un número cercano a los 420.000 volúmenes (Abellán 1988, p. 493; Marañón Posadillo, 1954, p. 12). Es en el universo de este filósofo -reconocido en su tiempo por su osadía y su voluntad de difundir diferentes voces, diversos modos de pensar- en el que nos proponemos ingresar para rastrear la presencia de Spinoza en el siglo XVIII español. Y ello supone sumergirse en una propuesta excepcional que nos invita a contemplar el mundo sin prejuicios, que nos insta a utilizar nuestra propia razón y aventurarnos en la hazaña del pensamiento. Una invitación afín, sin duda, al espíritu del spinozismo.

opinión, la mayor importancia a la hora de comprender la lectura feijoniana del spinozismo.

3 Sobre el carácter ensayístico de las obras de Feijoo, considerado un pionero del género en la lengua española, puede consultarse: Bueno Martínez, 1966. 


\section{SPINOZA, IUDEUS ET ATHEISTA, Y EL ESPíRITU LIBERAL De Feijoo (o Teatro Crítico, Tomo VI, Discurso 2, $35^{4}$ )}

El Teatro Crítico -cuyo nombre responde a la acepción de «panorama general» que entonces poseía la palabra teatro- se titula también Discursos varios en todo género de materias, para desengaño de errores comunes. Esta declaración explícita del objetivo de Feijoo en el título del escrito responde a la misión que él mismo consagró para su filosofía: abordar problemas y autores que no eran frecuentemente trabajados en la España de su época, desterrando prejuicios y supersticiones, evidenciando errores, con la esperanza de encontrar aquellas sendas conducentes a la verdad. Dicha actitud crítica supuso el despliegue de un fuerte cuestionamiento a muchos aspectos de la práctica del catolicismo y la apertura a diversos temas del pensamiento moderno (Chiaramonte 2007, p. 31), gesto osado que despertó gran reconocimiento entre sus contemporáneos. En 1748 el rey Fernando VI lo nombró consejero, distinción que lo protegía del alcance de la Inquisición (de Olaso 1981); el papa Benedicto XIV confesaba leer con gusto sus trabajos y mostró abierta simpatía por su obra, que contó también con el respaldo de la orden benedictina. Cierto es que esta situación favorable se enmarca en un mundo cultural que comenzaba a verse impregnado de disidencias, atravesado por "la nueva situación posterior al fin de las guerras de religión y, sobre todo, al advenimiento de los Borbones al trono de España, con el afianzamiento de las tendencias regalistas, del espíritu de tolerancia, y la disminución del peso de la Inquisición" (Chiaramonte 2007, p. 32). Esto permite contextualizar las numerosas ediciones de los escritos de Feijoo y su recepción amable por parte de algunos sectores del catolicismo y del poder político, atendiendo, sin embargo, a no menoscabar la osadía y profundidad del gesto crítico de su autor. Porque la cruzada del benedictino, que llegó a trasponer las fronteras del Índex y le valió desde fuertes críticas hasta la enemistad de algunos inquisidores, ${ }^{5}$

4 Abreviamos: Teatro Crítico con «T» el número de tomo en romanos, el número de discurso en arábigos, consignando luego el número de párrafo dentro del discurso. Citamos según: Biblioteca Feijoniana, Edición Digital de las Obras de Feijoo, Biblioteca Filosofía en Español, Oviedo, Fundación Gustavo Bueno, 1998.

$5 \mathrm{Al}$ respecto, Chiaramonte afirma: «Es cierto que no eran elogios lo único que encontraba Feijóo a lo largo de la edición de sus obras. Los sectores a los que su crítica hería seguían siendo fuertes [...]. De manera que, por ejemplo, Feijóo recibió fuertes críticas, con acusaciones algunas de ellas de mal católico - por elogiar a Bacon-, o de impío - por probar que era falso el milagro de las flores de San Luis del Monte (1743), episodio en el que quedó maltrecho por los ataques, pues hasta tuvo que sufrir la reacción adversa de amigos suyos-» $(2007$, pp. 32, 33). El autor aporta, también, una carta de Feijoo en la que éste confiesa preocupación por la designación de un «Inquisidor general amantísimo de la antigualla» que sería «muy desafecto» a su persona y a sus libros. 
logró el arduo cometido de poner en circulación ideas, debates, en un horizonte caracterizado por la censura y, quizás, por cierta quietud filosófica (de Olaso 1976, pp. 196, 197). ${ }^{6}$

El generoso intento de sacudir la pereza intelectual española -señala Méndez Bejarano en su Historia de la filosofía en España hasta el siglo XX - que tal será siempre el mérito de Feyjóo, se tradujo en el Teatro crítico, reunión de disertaciones sobre puntos importantes de la filosofía y del estado social en las cuales predomina el pensamiento de los naturalistas. Feyjóo se presenta con sentido crítico, casi adoptando la actitud de un Bacon español, dispuesto a romper lanzas con la dialéctica y la cosmología de las escuelas y a ahuyentar las absurdas creencias o prejuicios que bullían en los cerebros de sus compatriotas (Méndez Bejarano 1929, p. 346). ${ }^{7}$

No es casual, entonces, que sea en el marco de las obras de Feijoo donde se menciona a Spinoza y se consignan referencias a su pensamiento, cuya presencia en la filosofía española de la época era exigua. Esta ausencia casi total de Spinoza, por lo menos hasta el año 1759, vuelve a las alusiones del padre Feijoo verdaderamente relevantes para reconstruir la recepción del spinozismo en España. Y es posible ofrecer algunos lineamientos para conjeturar por qué es allí que se alude a este pensador acusado de impío, de hereje, en una coyuntura atravesada todavía por la censura y la Inquisición. En principio, es menester señalar que Feijoo cita y toma información de periódicos, revistas (por ejemplo, el Journal des Savants o las Mémoires de Trévoux), en las que se encuentran referencias a Spinoza y a su sistema; también conoce y consulta obras como el Grand Dictionnaire historique de Louis Moréri, que lo mantenían

6 Olaso recuerda que en su obra de madurez Cartas Eruditas y Curiosas, Feijoo debió «inventarse un interlocutor que lo ayudara a hacer progresar sus meditaciones» y agrega, respecto de las reservas que muestra el benedictino en aquella obra debido al clima intelectual de su época: «Así nos explicamos mejor sus temores a la censura eclesiástica. En una nota al primer discurso acata respetuosamente la máxima de un padre de la Iglesia según la cual "es peligroso decir incluso cosas verdaderas de lo divino"; se disculpa por su doctrina "nueva" y pide que no se la considere como "aserción positiva" sino como razón de dudar contra la doctrina común».

7 Además del mencionado gesto crítico, ilustrado, la obra de Feijoo es distinguida por su prosa y estilo. Puede leerse en un artículo de la escritora y activista Concepción Arenal: «En los escritos, como en las personas, hay diferentes géneros de belleza; la del estilo de Feijoo viene principalmente de la energía. Y no es que le falte gracia, pompa y galanura, no; es abundante y armonioso; pero su carácter distintivo es la fuerza: cortado, conciso, sentencioso, pone en relieve el pensamiento con los claros oscuros de la espontánea antítesis, medio eficaz de persuasión; [...] La lógica de Feijoo es inflexible, y su dialéctica poderosa siempre que discute con libertad. Al combatir una preocupación, cuando nos parece que ha sido considerada por todas sus fases, aún halla algunas nuevas; cuando creemos que están apurados todos los argumentos aún tiene otro y otros muchos con que abruma» (Arenal Ponte 1877, pp. 115, 116). 
al tanto de los debates filosóficos de la primera modernidad, y se demuestra lector del calvinista Pierre Bayle, especialmente del Dictionnaire historique et critique (Bahr 2004, 2005). Por todo ello, es de esperar que tuviera alguna noticia del impacto del spinozismo y de las discusiones surgidas en torno a la publicación del Tratado teológico-político. Por otro lado -como abordaremos más adelante- el benedictino conoce la filosofía de Descartes, se detiene en ella, y reconoce a Spinoza como un «sectario sobresaliente» (T. II, 1, 21) del cartesianismo. En tanto tal, entonces, su figura también revestiría interés para él. Pero, además, en línea con su mencionado espíritu ilustrado, Feijoo muestra una actitud liberal y tolerante frente a dos rasgos que caracterizaron históricamente a la figura de Spinoza y que pueden haber tenido especial fuerza negativa en España: ser judío y ser calificado de ateo. Quisiéramos detenernos en ciertas consideraciones que el benedictino despliega respecto de estos dos rasgos, para converger finalmente en un examen de la primera referencia explícita al nombre del filósofo holandés que abordaremos aquí, a propósito de su ateísmo.

En el discurso titulado Observaciones comunes del quinto tomo de su Teatro Crítico, Feijoo lleva adelante una defensa del pueblo judío frente a prejuicios de carácter ofensivo y malintencionado, que dejan entrever un clima de imperante hostilidad al cual desea oponerse. En principio, se propone refutar dos opiniones: que los individuos de la nación judaica tienen cola y que los médicos judíos sacrifican a uno de cada cinco pacientes cristianos que visitan (T. V, 5, 13). El absurdo de estas creencias a los ojos de lectores contemporáneos no debe conducir a menospreciar su masividad y su vigencia en la España de aquella época, su carácter común, que denota una rivalidad hegemónica hacia el pueblo judío. Respecto de la primera, el benedictino califica como «totalmente inverosímil» la posibilidad de que Dios produzca una excepción tan extraña en la organización corporal humana, que iría en contra de las leyes mismas de la naturaleza, y atribuye esta fábula al odio existente hacia aquella nación. Respecto de la segunda opinión, argumenta que «no hay médico alguno que no ame más el interés y crédito propio, que la ruina ajena; así procurará la restauración de los enfermos, de donde pende su crédito, y por consiguiente su interés» $(\mathrm{T}$. V, 5,14$)$, remarcando, además, que de existir dicho plan macabro no sería realizable a largo plazo «pues a dos o tres meses de experiencia todos huirían de un Médico tan fatal, aún cuando lo atribuyesen a ignorancia o infidelidad». Para comprender el arraigo de este prejuicio, podemos recordar que, justamente, «una de las razones que se invocó para expulsar a los judíos [de España] en 1492 fue la sospecha de que el médico real, judío, había envenenado al infante Don Juan, hijo de Fernando e Isabel» (de Olaso 1976, p. 190). Así, en un contexto en el que reinaba la intolerancia e incluso la persecución hacia el pueblo judío, Feijoo se coloca 
como su defensor frente a la difamación generalizada que implicaban ciertos prejuicios ofensivos e injuriosos. Posición que se enmarca en su batalla contra el odio y la superstición, en una gran «cruzada igualitaria que emprendió respecto de razas y minorías» (ibidem).

$\mathrm{Su}$ actitud hacia el ateísmo también denota un espíritu respetuoso, moderado, abierto. En el primer discurso del sexto tomo de esta obra, titulado Paradojas politicas y morales, Feijoo afirma: «No hay hombre de buen entendimiento, que no sea de buena voluntad» (T. VI, 1, 123), apreciación que defiende a pesar de confesar que puede parecer una quimera para la mayoría de los mortales. «Ninguno habrá, que no asegure haber visto, y tratado alguno, o algunos sujetos de bellísima capacidad, y de perversa inclinación» (ibídem), sostiene. Pero, al contrario, él juzga que ello es imposible. Entendiendo por «hombres de mala voluntad» aquellos en quienes reinan vicios perjudiciales para la sociedad humana, aquellos que demuestran absoluta indiferencia por el bien del prójimo, por el bien público, y buscan solamente el provecho propio, argumenta que nunca un entendimiento claro dejará caer a la voluntad en estos vicios. Porque un hombre de buen entendimiento inmediatamente comprende la distancia que supone con la naturaleza racional el hacer mal a otro de forma voluntaria. Un ejemplo de ello - señala- es la conducta quieta, pacífica, negada a toda violencia o injusticia, de hombres reputados por ateístas como lo fueron Plinio el Viejo entre los antiguos o Hobbes entre los modernos. Y es posible comprender esta aparente paradoja porque, para Feijoo, «la existencia de Dios, aunque evidentísima, no es evidente por sí misma respecto del entendimiento humano» (T. VI, 1, 124), mientras que la fealdad de las acciones viciosas es evidente por sí misma. Esta consideración del ateísmo que no lo vincula con una amenaza para la moral ni con un estorbo para la virtud mientras se acompañe de buen entendimiento puede ser rápidamente trasladada al caso de Spinoza. Luego de aquellas afirmaciones es lícito sospechar que Feijoo no comulgaba con las acusaciones hacia el filósofo holandés de ser un hombre monstruoso, depravado, vicioso, nacidas de considerarlo como ateo. Sospechas que son confirmadas en el discurso siguiente cuando el benedictino hace alusión explícita al nombre de Spinoza.

En Apología de algunos personajes famosos en la historia Feijoo se detiene en la figura de Epicuro y busca defenderlo de los relatos que lo imaginaban consumido en «lascivias, glotonerías, y embriagueces» (T. VI, 2, 21) por haber identificado la suprema felicidad con el deleite o placer. ${ }^{8}$ Para

8 Así reflexiona Feijoo: «Constituía Epicuro la suprema felicidad en el Deleite: doctrina equívoca, entretanto que se mira en esta generalidad, porque el deleite es indiferente a honesto, y torpe. Pero el vulgo comúnmente al oír la voz Deleite, la determina a mala significación, porque, según su grosero modo de entender, apenas percibe otros deleites, que los de la incontinencia, y 
ello aporta testimonios biográficos y analiza algunos puntos centrales de su doctrina. Confiesa que las tesis sobre la divinidad, el aspecto de la religión, «es el más crítico respecto de Epicuro» (T. VI, 2, 34), frente a lo que se propone examinar si su concepción teológica «hacía consecuencia a la desreglada vida, que le atribuyeron sus émulos, y que vulgarmente se le imputa» (T. VI, 2, 35). La conclusión de Feijoo es fácilmente predecible: Epicuro no puede ser considerado un sujeto vicioso o inmoral solo por el hecho de creer que no hay Dios. Y para sostenerlo esgrime como prueba el caso de Spinoza. «El famoso ateísta de estos tiempos Benito Espinosa -afirma- vivía siempre retirado, y ocupado siempre, ya en el estudio, ya en fabricar telescopios, y microscopios: hombre sobrio, continente, y pacífico» (ibídem). Detengámonos un momento en esta breve referencia. Resulta interesante que aquí Feijoo quiere separar la condición de ateo de Epicuro, su negación de la existencia de Dios, del hecho de llevar una vida viciosa, lasciva, para lo cual recurre a la figura de Spinoza. Este último es colocado, así, como paradigma de virtud, como un ejemplo de buena conducta y su caso (que es citado estratégicamente) representa para Feijoo una exitosa defensa de Epicuro, un medio para refutar acusaciones infundadas e injustas. En ese sentido, la aparición de Spinoza nos dice algo respecto de la consideración que el propio Feijoo podría guardar sobre él, también víctima de agravios pese a una conducta intachable. En la defensa a Epicuro través de Spinoza subyace, entones, una reivindicación de aquel «famoso ateísta». Pero además, esta referencia no conlleva ninguna apreciación negativa, ningún juicio respecto de la filosofía spinozista o de las obras atribuidas al pensador holandés. Entonces, su figura sirve como un elemento de prueba contra las calumnias de inmoralidad esgrimidas por sus contemporáneos a los ateos, sin necesidad de agregar luego ninguna salvedad derivada de su sistema filosófico. No se incluye una advertencia respecto de los abismos a los que podrían conducir sus escritos, ni se introducen consideraciones negativas o siquiera términos peyorativos al abordar su caso. Spinoza pareciera ser para Feijoo uno de aquellos hombres de buen entendimiento y, por eso, de buena voluntad que en tanto tal no puede ser acusado de conductas pecaminosas o inmorales. Así, la aparición de este retrato resulta significativa para nuestro propósito en tanto representa una estimación desapasionada de él, una valoración de su persona independiente de la acusación de ateísmo que pesaba sobre sus hombros.

Estos argumentos que podemos rastrear en las obras de Feijoo, este

destemplanza, o por lo menos estos tiene por los mayores. La ruda inteligencia del vulgo alentó a los émulos para infamar la doctrina de Epicuro, como que colocaba toda la Bienaventuranza en la sensualidad, y la gula. Fue fácil derivar luego la acusación de la doctrina a las costumbres, porque siendo evidente, que todos los hombres con apetito innato desean ser felices, era consiguiente, que Epicuro buscaría con ansia aquellos objetos, en quienes creía consistir la felicidad» (T. VI, 2, 21). 
espíritu liberal hermanado con una voluntad de abatir supersticiones, permite conjeturar que los estigmas asociados al spinozismo no representaron un escollo para el benedictino a la hora de acercarse a Spinoza. No pudieron convencerlo, sin más, de su carácter herético. Quizás por eso encontramos en sus escritos las principales referencias a la filosofía spinozista en la España de aquellos años. Simples menciones, alusiones al nombre de aquel judío ateo que, sin embargo, rompen el silencio dominante que acataba, obediente, la censura y el rechazo contra aquellos manuscritos malditos. Dicha peculiar moderación con la cual Feijoo aborda problemas, prejuicios, autores que resultaban problemáticos en su entorno intelectual no debe perderse de vista, incluso en aquellos pasajes en los que el benedictino parece estrechar manos con la ortodoxia. Moderación que ilustra la apuesta verdaderamente filosófica de este autor, su gesto de hacer de la filosofía una actividad que trascienda las ataduras de los dogmas para volverse un ejercicio colectivo e intersubjetivo.

\section{III. "LA SABIDURÍA DEL MUNDO ES TUMULTUANTE, Y GUERRERA" (o TeAtro CRítico, Tomo II, Discurso 1, 25)}

La primera, y también más sustanciosa, alusión al nombre de Spinoza en el Teatro Crítico Universal se encuentra en el segundo tomo, en el discurso Guerras Filosóficas. Como lo indica su nombre, en esta sección Feijoo aborda críticamente lo que considera verdaderas batallas desatadas en virtud del ejercicio de la filosofía, en las cuales las ideas se vuelven trincheras, campos de combate. Estos intercambios entre pensadores, a su pesar, terminan pareciendo más «borrascas que disputas: en cuyos escritos a cada paso se leen las acusaciones de ignorancia, de rudeza, a veces también de impiedad, en sus contrarios» (T. II, 1, 2). Y aquello que señala como la causa del problema es que las doctrinas son tomadas por los filósofos como sectas y, en tanto tales, son imbuidas de un manto de verdad incuestionable que los lleva a atacar a quienes las impugnan (T. II, 1, 3). Desde este momento, aquellos que deberían poner en práctica su razón, que deberían dejar de lado sus prejuicios en pos de buscar la verdad, se convierten en fieles y obedientes seguidores de los principios que hubieron adoptado. Entonces, estas confrontaciones no representan ejercicios genuinos de pensamiento sino enfrentamientos estériles, agresivos, que responden a devociones personales y a fanatismos.

Feijoo se dedica a analizar, específicamente, una polémica que estalla con fuerza en España en los años siguientes al ascenso al trono de Felipe $\mathrm{V}$ y atraviesa el panorama intelectual de la época. Nos referimos a la disputa entre los llamados novatores (partidarios de filosofías nuevas, que se alejaban del pensamiento tradicional de la escolástica) y los aristotélicos (Ricca

9 T. II, $1,18$. 
2008). ${ }^{10}$ En Guerras filosóficas se ve retratada la persecución desplegada por estos últimos hacia los admiradores y defensores de Descartes, Gassendi o cualquiera que se apartara de los principios de la escolástica. Se los acusaba de ser «sospechosos en la Fe», sufriendo por ello desde castigos disciplinatorios hasta, en algunos casos, la muerte. Para ilustrar el ensañamiento que estas contiendas despertaban, el benedictino narra el asesinato del profesor Pedro del Ramo en la Noche de San Bartolomé, quien había criticado públicamente a Aristóteles y se había esforzado en mostrar sus contradicciones.

Los discípulos de Carpentier, y de otros Profesores enemigos suyos -relatasacándole de una cueva, donde se había escondido, después de darle muchas heridas, le arrojaron por una ventana; y no bastó para saciar la ira de los matadores, ver que al golpe saltaron las entrañas de su cuerpo; sino que le arrastraron, azotándole por las calles, donde quedó el cadáver dividido en varios trozos (T. II, 1, 7-8). ${ }^{11}$

Estos mecanismos de disciplinamiento y desacreditación aplicados sobre las filosofías nuevas se basan, primeramente, en calumnias hacia sus exponentes, en agravios e insultos, que son devueltos también por los cartesianos y gassendistas hacia Aristóteles. Así, en estas disputas no se destacan las argumentaciones, las demostraciones, los razonamientos, sino únicamente las injurias, el «fuego de pólvora destinado a herir y no a brillar» (T. II, 1, 18).

Los que bravean de este modo -sentencia el padre gallego-no buscan la verdad: pues para lograr este fin, no los estorba quien los contradice, antes los ayuda. Más fácil será encontrarla buscándola muchos, y por opuestos rumbos, que pocos, siguiendo siempre un camino. Sólo atienden a establecer el predominio de la opinión que se ha abrazado. En la lid de opiniones, todos los doctos debieran ser neutrales, y casi todos son faccionarios (ibidem).

La crítica feijoniana a esta forma belicosa de poner en ejercicio la praxis filosófica, que puede desembocar finalmente en la violencia, ofrece en este pasaje, como contrapartida para zanjar aquellas guerras, una defensa de la

10 Guillermo Ricca desarrolla ciertos elementos particulares de la disputa entre novatores y aristotélicos, aborda el discurso Guerras filosóficas y se propone establecer un diálogo entre Spinoza y Feijoo siguiendo los puntos medulares del artículo de Olaso (1976) «Spinoza y nosotros».

11 Ricca menciona también el caso de Diego de Zapata, judío converso perseguido por la inquisición que «es apresado en 1725 y obligado a confesar bajo tortura que a los 12 años había sido iniciado en la religión judía por su madre y que seguía practicando sus ritos, incluso cuando ejercía de médico en Madrid» (Ricca 2008, p. 7). 
libertad de filosofar, exhortando a trascender el ámbito de la opinión para proyectarse hacia una búsqueda de la verdad que sea compartida, colectiva. Si bien esta perspectiva aparece tímidamente en el texto, entre líneas, conduce a pensar que es un trabajo intersubjetivo, mancomunado, el que disiparía los enfrentamientos y oposiciones a partir de concebir la actividad de pensar como un horizonte común.

Dicho carácter sectario de la filosofía responde, para Feijoo, a la falta de inteligencia de algunos «hombres de mucha frente y poco fondo» (T. II, 1, 19), pero también a las actitudes de otros que obran «no por falta de reflexión sino por sobra de política» (ibídem). Estos últimos saben bien «que los necios son infinitos, y que a todos los que lo son, persuade más el estrépito de las voces, que la fuerza de los discursos» (ibídem), y utilizan este recurso para intervenir en disputas que se pretenden filosóficas con propósitos ajenos a los estrictamente intelectuales. Por ello, son quienes más se benefician de las divisiones y confrontaciones, enmascarando sus propios intereses detrás de ellas. «Adonde se descubre más esta maliciosa política - prosigue- es en la acusación, que recíprocamente se hacen los Filósofos, de ser sus doctrinas incompatibles con los sagrados Dogmas»(T. II, 1, 20), ${ }^{12}$ acusación que, entonces, pareciera tener poco de filosófica y mucho de astucia política. Es interesante que antes de abordar aquellos argumentos que fueron adoptados para sostener la imputación de impiedad, Feijoo ya está anunciando su veredicto respecto de ella: proponerse refutar o, por lo menos, objetar un sistema de pensamiento a partir de condenarlo como hereje es abandonar el campo del debate reflexivo, poniéndose de parte de la ortodoxia y buscando asilo en ella. En la disputa que nos ocupa, esta estrategia fue desplegada especialmente por los escolásticos, quienes avanzaban en dos frentes: primero, esgrimiendo el carácter sospechoso de las filosofías adversarias por ser nuevas y, luego, su potencialidad de conducir al ateísmo.

El benedictino se aboca a desarmar estos argumentos para mostrar, finalmente, su falta de asidero. Respecto de lo primero, se pronuncia en defensa de la novedad en la filosofía, evidenciando una vez más un espíritu opuesto al dogmatismo y a las ideas anquilosadas. «La novedad en las cosas puramente Filosóficas no es culpable» (T. II, 1, 22), afirma. «En el Reino intelectual sólo a lo infalible está vinculado lo inmutable. Donde hay riesgo de errar, excluir toda novedad, es en cierta manera ponerse de parte del error»

12 Feijoo sostiene que «el empeño, en que todos se ponen, de que la filosofía que impugnan está mal avenida con lo que dicta la $\mathrm{Fe}$, muestra que en esto se procede con el mismo motivo de algunos Príncipes, que siempre que hallan escotadura para ello, hacen en sus manifiestos, la guerra que emprenden, causa de Religión». Ricca encuentra en estos pasajes argumentos muy similares a la crítica que hace Spinoza de lo teológico político y afirma que no resulta extraño que a continuación Feijoo examine el «caso Spinoza» (Ricca 2008, p. 10). 
(ibídem), concluye. Y agrega, replicando el mismo razonamiento contra los aristotélicos:

Si la novedad fuera mancha de la doctrina, todas las doctrinas serían mal nacidas, porque todas fueron engendradas con esa mancha. Todas fueron nuevas algún tiempo. La de Aristóteles primero fue nueva en el mundo, y después fue nueva en la Iglesia; por lo menos en cuanto al uso de explicar con ella la Teología Escolástica (ibídem).

Una vez desestimado el primer argumento, Feijoo avanza hacia la acusación proferida contra las filosofías de Descartes y Gassendi de conducir al ateísmo. Y es aquí donde aparecen las referencias a Spinoza. Para sostener dicha imputación, los escolásticos «notaron en la Doctrina de Gasendo ser la misma del impío Epicuro; y a la de Descartes impusieron el feo borrón de conducir el espíritu al Ateísmo, probando, o esforzando esto con el ejemplo del Ateísta Benito de Espinosa, Sectario sobresaliente de Descartes en la Filosofía» (T. II, 1, 21). Feijoo se propone mostrar que estas acusaciones son infundadas y que, nuevamente, pueden «retorcerse contra los Aristotélicos» (T. II, 1, 25). Respecto de lo segundo, recuerda que Averroes, «el más fino sectario de Aristóteles» (T. II, 1, 26), no profesó religión alguna y que, también, Lucilio Vanini, quien «no siguió otra Filosofía que la de Aristóteles, estudiada en los Comentarios de Averroes» (ibídem), fue quemado vivo en 1619 acusado de ateo. «Si dos Ateístas Aristotélicos no prueban contra la Filosofía de Aristóteles, tampoco un Ateísta Cartesiano probará contra la Filosofía de Descartes» (ibídem), remata. Abordando específicamente el caso de Spinoza, dedica un párrafo a trazar una biografía sucinta del filósofo holandés y se interroga por las causas de su ateísmo:

Benito Espinosa fue Cartesiano y Ateísta; pero no nació en él el Ateísmo del Cartesianismo. Profesó este hombre primero el Judaísmo, como hijo de padres Judíos, que fugitivos de Portugal, hicieron en Ámsterdam su asiento, y habiendo llegado a alcanzar las implicaciones de aquella secta, después que inútilmente buscó en los Doctores de ella solución en sus dificultades, antes incurrió su ojeriza por la duda; la abandonó, renunciando al mismo tiempo a toda Religión. Algunos dicen que mucho antes tenía ocultas en su espíritu las semillas del Ateísmo, comunicadas por un Médico Alemán, en cuya Escuela (que la tenía de Gramática) había estudiado la latinidad. Otros por el contrario pretenden, que mucho después de acabar todos sus estudios, cuando ya escribía libros, le llevaron a este precipicio sus cavilaciones: porque en la demostración geométrica de los Principios de Descartes, que imprimió a los treinta años de edad, se muestra muy distante del Ateísmo. Cualquiera de las dos cosas que se diga, parece que no vino de la Filosofía de Descartes el ateísmo de Espinosa (T. II, 1, 25). 
Examinemos, entonces, estos pasajes. En principio, es interesante desatacar que, nuevamente, en su alusión a Spinoza (y esto puede hacerse extensivo a todas las referencias presentes en el Teatro Crítico) Feijoo no concluye nada malo respecto de su persona ni tampoco de su filosofía. De esta última, de hecho, sólo dice que sigue al cartesianismo y que es sobresaliente en ese aspecto, ponderación que denota una consideración positiva, en un sentido valorable, del spinozismo. Si bien este retrato pareciera tomarse del artículo dedicado a Spinoza en el Diccionario de Bayle (de Olaso 1976, p. 184; Ricca 2008, p. 8) no se incluyen aquí ninguna de las críticas que Bayle profiere contra Spinoza y sus obras, quien por ejemplo califica al Tratado teológicopolítico como un libro pernicioso y detestable (Bayle 2010 [1702], p. 334). No encontramos, entonces, una estimación negativa por parte del benedictino. Lo que sí aparece cada vez que se menciona al filósofo holandés es el mote de ateo. Pero, ateniéndonos a la posición feijoniana respecto del ateísmo a la que nos hemos referido más arriba, es posible afirmar que esto no presenta en sí mismo un motivo de condena. Como dijimos, en los textos de Feijoo el ateísmo no se vincula con una conducta inmoral, no representa una actitud que en sí misma tenga consecuencias éticas negativas, no se identifica con una mala voluntad. Así, este pasaje en el que se aborda la figura de Spinoza evidencia que Feijoo conoce al filósofo, tiene noticia de algunas de sus obras (cita, por ejemplo, los Principios de filosofía de Descartes) pero no manifiesta ánimos de criticarlo explícitamente. Además, cabe destacar que al final del segundo tomo, en el que se inscribe este discurso, el benedictino vuelve a mencionar a Spinoza en su Índice alfabético de las cosas más notables. Este Índice es un apartado, con el que concluye cada volumen, en el que se nuclean diferentes conceptos y personajes importantes que han sido mencionados a lo largo del texto. Allí se presenta una alusión muy breve en la que se vuelve a señalar que «Benito Espinosa no fue Ateísta por ser cartesiano» (T. II, Índice alfabético de las cosas más notables, «Benito Espinosa»). Esta aparición evidencia que el holandés representa para Feijoo una figura notable. Lo cual nos remite a aquella otra referencia que ya hemos abordado aquí, presente en el sexto tomo, en el discurso dedicado a Epicuro, donde el benedictino se refiere al carácter continente y pacífico de Spinoza. Allí también lo caracteriza como una persona famosa, que no necesita de mayor presentación o de preámbulos ante el público lector, pese al silencio que reina en torno a su nombre en los escritos filosóficos de la región. Por otro lado, si bien la referencia biográfica presente en Guerras filosóficas es acotada, el marco textual y argumentativo en el que aparece es elocuente. Spinoza fue un protagonista indiscutido de esas guerras que se propone pensar Feijoo: su sistema fue atacado a través de agravios e injurias dirigidos a su persona, consagrándose como uno de los más célebres herejes de la modernidad. Por lo que el examen crítico que realiza el 
benedictino de estos mecanismos de desacreditación, a los que describe como agresivos y poco filosóficos, representa una defensa de aquellos sobre quienes se aplicaron y de sus sistemas. Una defensa que bien puede estar dirigida a casos como el de Spinoza, cuyo nombre casualmente emerge con el fin de resguardar el pensamiento de Descartes de acusaciones infundadas.

Antes de concluir, es menester dedicar unas últimas palabras a Guerras Filosóficas. Porque hacia el final del discurso Feijoo pareciera incurrir en una aparente contradicción sobre la que resulta interesante reflexionar. La estrategia argumentativa que da comienzo a este apartado se dirige a respaldar a los novatores en su disputa con los escolásticos. Para ello, por un lado se evidencia la paradoja que supone señalar como sospechosas a las filosofías nuevas solo por ser recientes y también se sostiene que no es posible acusarlas de conducir al ateísmo basándose únicamente en que algunos de sus partidarios fueron considerados ateos. Ahora bien, en los párrafos siguientes Feijoo realiza un análisis del sistema aristotélico -contraponiéndolo con la filosofía corpuscular y el sistema cartesiano- que lo lleva finalmente a inclinarse en favor de aquel. Después de un abordaje detallado de algunas tesis relativas a estos sistemas nacientes, el benedictino concluye sorprendentemente que ellos son incompatibles con los dogmas sagrados y que, como tales, conducen muchas veces a afirmaciones contrarias a la fe (T. II, 1, 36-55). Por lo tanto, se sostiene en el texto, de algún modo, aquella imputación de heterodoxia contra las filosofías modernas que esgrimían los escolásticos. ¿Cómo entender esta aparente inconsecuencia? ¿Cómo determinar la posición del padre gallego en el marco de esta disputa? Al respecto es posible formular diversas líneas de lectura, múltiples visiones interpretativas, que otorgan diferentes perspectivas sobre estos pasajes, sobre la figura de Feijoo y, en ese sentido, aportan a una comprensión de la trama en la que emerge el nombre de Spinoza. Aquí traeremos a consideración simplemente algunos elementos.

En principio, atendiendo a aquello que el mismo Feijoo despliega en el final de este discurso, es posible distinguir, para él, dos maneras en las que poner en práctica el ejercicio del pensamiento. Por un lado, la actividad filosófica se considera como una «escala para subir a la Teología Escolástica» (T. II, 1, 52), es decir, como aquello que «prepara el tránsito a la luz revelada» (de Olaso 1976, p. 186), como una propedéutica, una introducción al estudio de las Sagradas Escrituras. Pero también la filosofía es, en palabras de Feijoo, «un instrumento para examinar la naturaleza» (T. II, 1, 52), una forma de conocer el mundo que nos rodea, tarea en la cual los filósofos pueden, «sin sujetarse servilmente al Peripatetismo, buscar la verdad por el camino que les parezca más derecho; pero sin perder jamás de vista los Dogmas Sagrados, para no tropezar en alguna sentencia filosófica incompatible con cualquiera de ellos» (ibídem). Esta concepción bifronte permitiría explicar por qué el 
benedictino pronuncia una defensa de los modernos, de los sistemas nuevos, en tanto diferentes perspectivas desde las cuales explicar el mundo natural pero al mismo tiempo proclama al aristotelismo como única filosofía compatible con los dogmas sagrados. Respecto de lo primero, Feijoo defendería la libertad de filosofar mientras que respecto de lo segundo reconocería la autoridad de la escolástica. Sin embargo, esta posición no es presentada de manera tajante sino que es matizada por el mismo Feijoo, quien finalmente recomienda

huir de dos extremos, que igualmente estorban el hallazgo de la verdad. El uno es la tenaz adherencia a las máximas antiguas: el otro, la indiscreta inclinación a las doctrinas nuevas. El verdadero Filósofo no debe ser parcial, ni de este, ni de aquel siglo. En las Naciones extranjeras pecan muchos en el segundo extremo: en España casi todos en el primero (T. II, 1, 54).

Y esta exhortación a buscar el «justo medio» no parece compatible con una férrea convicción de ortodoxia. Por el contrario, la identificación de una «tenaz adherencia a las máximas antiguas» como un extremo pernicioso resulta bastante disidente. Por lo que es posible concebir el cambio de dirección abrupto de Feijoo en favor de los aristotélicos como una estrategia de disimulo, de autocensura, «viejas armas defensivas ante adversarios tan temibles como la Inquisición» (Chiaramonte 2007, p. 33). ${ }^{13}$ Esta estrategia, «más que a intervenir con tesis propias y enfáticas acerca de las potestades y límites de la razón, apunta a escamotear adversarios peligrosos y a exponer pensamientos que en el marco de las disputas de la época y de cara al abanico de destinatarios eran tan sólo materia de censura» (Ricca 2008, p. 11-12). En otras palabras, la preocupación del benedictino no sería tomar una posición clara en la disputa sino poner en diálogo, en circulación, autores y modos de pensar diversos. El objetivo sería dar a conocer a los lectores del Teatro Crítico (cuyo universo de destinatarios incluye al magisterio eclesiástico, a la corona pero también al gran público español y americano) las implicancias de esta polémica y sus consecuencias. Pero sin correr el riesgo de la sospecha, la impugnación o, aun peor, de la persecución. Y efectivamente Feijoo logra, en su despliegue de esta «compleja estrategia cultural» (de Olaso 1976, p. 182), presentar los diferentes argumentos que se ponen en juego y analizarlos rigurosamente, desde un punto de vista filosófico, sin tomar partido claramente por ninguno de los sectores involucrados. Así, la aparición de Spinoza resulta estratégica. Su presencia en el análisis de las guerras filosóficas permite

13 Este autor considera que las alegaciones de ortodoxia por parte de Feijoo pueden no ser totalmente sinceras, respondiendo más a una defensa contra la censura, «dado que su pensamiento constituyó una de las más efectivas críticas de la intolerancia, prejuicios, fanatismo, y otras características tradicionales del catolicismo español de su época». 
situarlo como uno de los protagonistas hacia los cuales se dirige la apología feijoniana de los sistemas nuevos. No parece, entonces, azarosa sino enmarcada en una cuidadosa partida de ajedrez en la que el benedictino cruza los límites de la censura, consciente de aquello que arriesga.

\section{PARA CONCLUIR}

Luego de este recorrido por las diferentes evocaciones a Spinoza en el Teatro Crítico $^{14}$ resulta posible pensar su figura en esta obra desde una triple perspectiva: se nos muestra, por un lado, como relevante, también como estratégica y, a la vez, como enigmática. La presencia de Spinoza en Feijoo resulta relevante en tanto constituye un pronunciamiento, una referencia sobre el filósofo holandés en un contexto en el que dominaba taxativamente el silencio, en el que operaba, incluso, la censura. El benedictino cita a Spinoza, alude a su pensamiento, desde una coyuntura y en una región en donde prácticamente nadie más lo hace. Y ese gesto fundacional, esa voluntad de nombrar, lo convierte en una fuente obligada para pensar la recepción del spinozismo en España en el siglo XVIII. Además, si bien Spinoza no tiene un lugar preponderante o protagónico, se vuelve una presencia recurrente, una figura que retorna, en la medida en que es mencionado en distintos discursos de diferentes volúmenes.

Por otro lado, las alusiones al filósofo holandés lo revelan como una figura estratégica en tanto su presencia es introducida cuidadosamente, desde una neutralidad que sorprende por su moderación pero que también se caracteriza por su distancia. Teniendo en cuenta, incluso, la censura que pesaba sobre su nombre, Feijoo decide acudir a Spinoza, convocarlo al diálogo filosófico. Y no lo hace al azar sino en diversos contextos argumentativos en los que su evocación se vuelve una pieza clave que no podría ser intercambiada por otra, cuyo lugar no es accidental sino táctico. Es interesante que el benedictino siempre aborde a Spinoza en vinculación con otros pensadores, que lo convoque como ejemplo, como caso, cuando se encuentra tratando problemas relativos a otros filósofos, pero sin dedicarle un tratamiento específico, un análisis exhaustivo a la filosofía spinoziana misma. Y ello, nuevamente, representa un movimiento calculado en la medida en que coloca al holandés como un interlocutor válido, en tanto lo introduce en las discusiones especulativas, pero sin comprometerse

14 Recordamos que en el Teatro crítico hay siete alusiones explícitas al nombre de Spinoza. De ellas, hemos abordado aquí seis: aquellas presentes en el discurso Guerras filosóficas del segundo tomo, la mención en el Índice de las cosas más notables de este volumen y aquella en Apología de algunos personajes famosos en la historia presente en el sexto tomo. No nos hemos detenido en la referencia propia del discurso Mérito y Fortuna de Aristóteles y de sus escritos, del cuarto tomo (T. IV, 7, 28). 
con una valoración sobre el spinozismo que podría implicar una posición problemática. Spinoza es, entonces, citado estratégicamente y también dejado de lado de forma meticulosa.

Aquello, sin embargo, conlleva que su figura en la obra de Feijoo sea, además, enigmática. Porque no se explicita una posición clara sobre él ni se despliega una lectura particular, una apreciación propiamente filosófica, un análisis que permita determinar el lugar de Spinoza. ¿Feijoo se limitó a reproducir un retrato de aquel judío holandés tomado de fuentes secundarias? ¿O accedió al sistema spinozista y fue interpelado por él a la hora de elaborar su propio pensamiento? ¿Toma Feijoo la crítica de Spinoza hacia lo teológicopolítico para pensar su coyuntura histórica e intelectual? ¿La concepción feijoniana sobre la filosofía como actividad libre y liberadora está inspirada en la propuesta spinoziana? Creemos que responder taxativamente a cualquiera de estos interrogantes implica, por un lado, aventurar sentidos y alejarse de lo estrictamente presente en los textos pero, además, supone cercenar este carácter enigmático, latente, sugestivo que el propio Feijoo le otorgó a la figura de Spinoza en su obra. Nos atrevemos a aventurar que esta presencia ausente es un rasgo constitutivo de la recepción de Spinoza en España y, también, posteriormente, en el continente americano; una clave de lectura a partir de la cual reflexionar sobre el destino de aquella filosofía en el mundo de habla hispana. Y, por eso, resulta interesante y valioso demorarse en aquellas preguntas, no apresurarse a responderlas sino sopesarlas íntimamente para dar lugar a sus múltiples y diversas respuestas.

\section{REFERENCIAS BIBLIOGRÁFICAS}

ABELLÁN, J.L. (1988). Historia crítica del pensamiento español. vol. 3: Del Barroco a la Ilustración (Siglos XVII y XVIII). Madrid: Espasa-Calpe.

ARENAL PONTE, C. (1877). «Juicio crítico de las obras de Feijoo», Revista de España, 217, pp. 110-117.

BAHR, F. (2004). «Feijoo y la historia crítica. O cómo aprovechar y corregir a Pierre Bayle», Bibliographica Americana. Revista interdisciplinaria de estudios coloniales, 1, pp. 29-40.

BAHR, F. (2005). «Pierre Bayle y las "Reflexiones sobre la Historia” del Padre Feijoo» en Cuadernos de Estudios del Siglo XVIII, 15, pp. 5-32.

BAYLE, P. (2010 [1702]). Diccionario histórico y crítico. Buenos Aires: El cuenco de plata.

BUENO MARTÍNEZ, G. (1966). «Sobre el concepto de “ensayo"» en El padre Feijoo y su siglo, tomo 1. Oviedo: Universidad de Oviedo, pp. 89-112.

CHIARAMONTE, J.C. (2007). La ilustración en el Río de la Plata. Buenos Aires: Sudamericana.

DE OLASO, E. (1981). «El padre Feijoo y el argumento del designio», Diálogos. Revista de Filosofía de la Universidad de Puerto Rico, 16, pp. 33-61. 
DE OLASO, E. (1976). «Spinoza y nosotros», en Homenaje a Baruch Spinoza. Buenos Aires: Museo Judío de Buenos Aires, pp. 179-198.

DOMÍNGUEZ, A. (2004). «España en Spinoza y Spinoza en España», en A. Domínguez (ed.) Spinoza y España. Actas del congreso internacional sobre «Relaciones entre Spinoza y España». Castilla: Universidad de Castilla-La Mancha, pp. 9-46.

DUJOVNE, L. (1941). Spinoza. Buenos Aires: Universidad de Buenos Aires.

FEIJOO, B. (1728). Teatro Crítico Universal, tomo segundo; (1734) tomo sexto. En Biblioteca Feijoniana, Edición Digital de las Obras de Feijoo, Biblioteca Filosofía en Español, Oviedo, Fundación Gustavo Bueno, 1998. Disponible en: http://www. filosofia.org/feijoo.htm

FERNÁNDEZ GARCÍA, E. (2018). «Ecos de Spinoza en María Zambrano», en J. Carvajal Cordón, M.L. de la Cámara y R. de Pablos (eds.), La encrucijada de los afectos. Ensayos spinozistas. Cuenca: Universidad de Castilla-La Mancha.

MARAÑÓN POSADILLO, G. (1954). «Consideraciones sobre Feijoo», La nueva España, Oviedo, sábado 3 de abril.

MÉNDEZ BEJARANO, M. (1929). Historia de la filosofía en España hasta el siglo $X X$. Madrid: Renacimiento.

PRÉLORENTZOS, Y. (1994). «Difusión y recepción del spinozismo en Francia desde 1665 hasta nuestros días», en A. Domínguez (ed.), Spinoza y España. Actas del congreso internacional sobre «Relaciones entre Spinoza y España». Castilla: Universidad de Castilla-La Mancha.

RICCA, G. (2008). «Ilustración radical y drama intelectual: Spinoza, Feijoo y las matrices diversas de lo moderno», A parte Rei. Revista de filosofía, 55. Disponible en: http://serbal.pntic.mec.es/ cmunoz11/ricca55.pdf

SOLÉ, M.J. (2011). Spinoza en Alemania. Córdoba: Brujas.

VĖRNIERE, P. (1954). Spinoza et la pensé française avant la révolution. París: Presses Universitaires de France.

Natalia SAbater es Licenciada en Filosofía por la Universidad de Buenos Aires. Es Profesora de Historia de la Filosofía Moderna de la misma universidad y becaria doctoral del CONICET.

Lineas de Investigación:

Baruch Spinoza y su recepción en la Argentina desde el siglo XVIII hasta mediados del siglo XX

Publicaciones recientes:

(2019): La destinación humana en Spinoza. Una reinterpretación de su proyecto ético. Buenos Aires: RAGIF ediciones. 
(2018): «Intuición intelectual y beatitud en la filosofía de Spinoa. Reflexiones sobre la posibilidad de una destinación humana», Hermeneutic. Revista digital de arte, crítica y filosofía, 16, pp. 67-84.

Correo electrónico: in_tenebriss@hotmail.com 
